\title{
Late Pleistocene hominin teeth from Laoya Cave, southern China
}

\author{
Song XING ${ }^{1}$, Ying GUAN ${ }^{1}$, Mackie O’HARA ${ }^{2}$, Huiyang $\mathrm{CAI}^{3}$, Xiaomin $\mathrm{WANG}^{1}$, Xing GAO ${ }^{1}$ \\ ${ }^{1}$ Key Laboratory of Vertebrate Evolution and Human Origins of Chinese Academy of Sciences, Institute of Vertebrate Paleontology \\ and Paleoanthropology, Chinese Academy of Sciences, Beijing 100044, China \\ ${ }^{2}$ Department of Anthropology, The Ohio State University, Columbus, OH 43210, USA \\ ${ }^{3}$ Guizhou Provincial Museum, Guiyang 550001, China
}

Received 17 February 2017; accepted 2 August 2017

\begin{abstract}
Recent fossil finds have complicated the picture of East Asian Late Pleistocene hominin taxonomy and morphology, necessitating analysis of more fossils with secure dates and stratigraphic contexts to better contextualize human evolution during this epoch. Field excavations at the Laoya Cave in Guizhou Province, China in 2013 recovered two isolated human teeth $\left(\mathrm{M}_{3}\right.$ and $\left.\mathrm{dm}^{2}\right)$. The teeth date from $\sim 21-24 \mathrm{kya}$, according to AMS radiocarbon dating. The present study provides detailed metric and non-metric descriptions of the Laoya teeth, and compares them with the dentition of other Late Pleistocene hominins (Neanderthals and fossil Homo sapiens from around the world) as well as chronologically earlier fossil hominins from the same geographical area (East Asian Early/Middle Pleistocene hominins). To achieve this, descriptive morphological observations, geometric morphometric analysis, and micro-computed tomography were employed. The lower third molar (LYC1) is characterized by several derived features, including the absence of a hypoconulid, the lack of C6 and C7, and an ' $\mathrm{X}$ '-type cuspal arrangement. The combination of traits expressed by LYC1 is unique, but very similar to other recent H. sapiens. However, the LYC1 also displays a suite of dental features that are not common in other East Asian Late Pleistocene fossil $\mathrm{H}$. sapiens: the absence of a hypoconulid, the presence of a middle trigonid crest, and a narrowed talonid relative to trigonid. This study of the Laoya teeth expands the known morphological diversity of East Asian Late Pleistocene hominin dentitions, and will contribute to a better understanding of the history of modern humans in this area.
\end{abstract}

Key words: fossil $H$. sapiens, dental materials, morphology, micro-CT

\section{Introduction}

Fossil hominins have been identified at around 50 Late Pleistocene sites across mainland East Asia (Wu and Poirier, 1995; Liu et al., 2010a, b; Li et al., 2017), but the absence of well-defined stratigraphy and/or radioactive dates has made it difficult to place many of these fossils in clear evolutionary contexts. Recently, several reliably dated and sites with clear stratigraphy have yielded new Homo sapiens fossils, which have revealed an unexpected morphological diversity and a longer chronology of our species in East Asia (Liu et al., 2010a, b, 2015; Curnoe et al., 2012; Bae et al., 2014). In this context, a new Late Pleistocene hominin site, Laoya Cave (LYC), was excavated in 2013. The excavation recovered new human fossil materials, which provide an important opportunity to investigate further the morphological diversity of hominins in the Late Pleistocene.

\footnotetext{
* Correspondence to: Ying Guan, Key Laboratory of Vertebrate Evolution and Human Origins of Chinese Academy of Sciences, Institute of Vertebrate Paleontology and Paleoanthropology, Chinese Academy of Sciences, No. 142 Xiwai Street, Beijing 100044, China.

E-mail: guanying@ivpp.ac.cn

Published online 29 September 2017

in J-STAGE (www.jstage.jst.go.jp) DOI: 10.1537/ase.170802
}

The Laoya Cave is located in Qingchang Town, Bijie City, Guizhou Province, southern China $\left(27^{\circ} 21^{\prime} 12.57^{\prime \prime N}\right.$, $105^{\circ} 11^{\prime} 8.46 " \mathrm{E}$ ) (Figure 1). Excavations there between 1983 and 1985 produced an abundance of lithic artifacts and fragmentary mammal bones (Guan et al., 2015). More recently, more than 2000 lithic and bone tools, faunal remains, seed husks, and carbon debris were recovered in the period JulyAugust 2013 (Guan et al., 2015). The deposit is divided into 11 stratigraphic layers (Figure 1), all of which contain mammal fossils, lithic tools, and carbon debris. Among the fossil materials, a fossil hominin isolated upper left deciduous $\mathrm{m}^{2}$ $\left(\mathrm{dm}^{2}\right)$ was recovered from Layer 2 and a fossil hominin isolated lower left third molar $\left(\mathrm{M}_{3}\right)$ was recovered from Layer 4 (see the Results section for the classification of the category for this tooth).

The lithic assemblage includes cores, flakes, and retouched pieces such as scrapers, points, choppers, etc. (Guan et al., 2015). To date, 13 mammal species have been identified in the assemblage: Macaca sp., Rhinopithecus sp., Rhizomys sp., Hystrix sp., Ursus sp., Ailuropoda melanoleuca, Arctonyx sp., Tapirus sp., Rhinoceros sp., Moschus sp., Muntiacus sp., Capricomsis sumatraensis, and various bovids. These faunal components are typical of southern China in the Late Pleistocene (Wang et al., 2016).

Sixteen samples of mammalian bones and carbon debris 


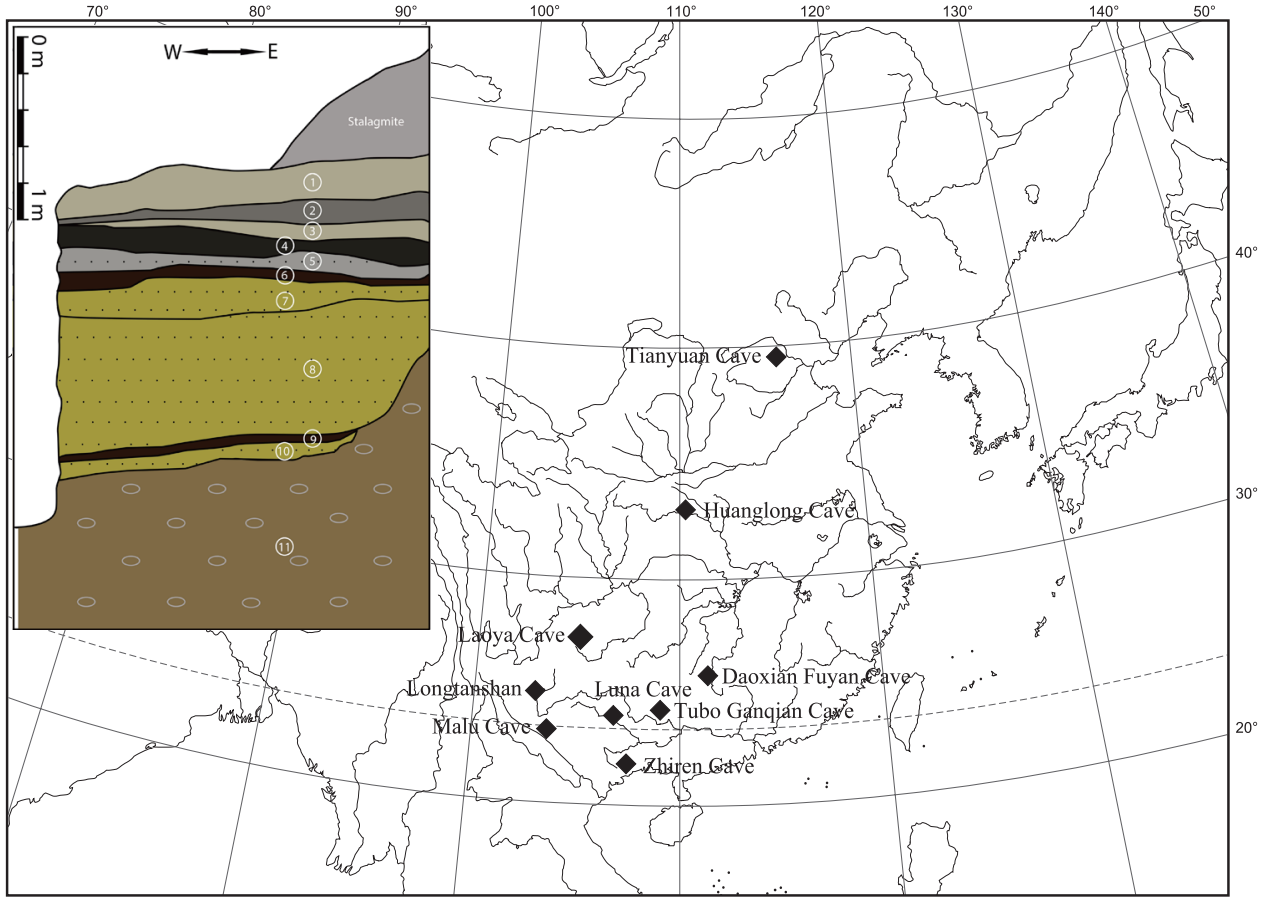

Figure 1. Geographic locations of Laoya Cave, other major Chinese Late Pleistocene hominin sites, and the stratigraphic sequences of the Laoya Cave (upper left). From top to bottom, the sedimentary compositions of each stratigraphic layer in the Laoya Cave are: (1) grayish yellow travertine, (2) gray-black clay, (3) grayish yellow clay, (4) black clay, (5) gray sandy clay, (6) dark brown ash, (7) yellow sandy clay, (8) yellow sandy clay, (9) dark brown ash, (10) yellow sandy clay, (11) gravel and silt.

Table 1. Radiocarbon dating results from the Laoya Cave site

\begin{tabular}{|c|c|c|c|c|c|}
\hline Layers & Method & Sample; pretreatment method & Uncorrected age (BP) & Corrected age (cal BP) & $\begin{array}{c}\text { Maximum layer range } \\
\text { (cal BP) }\end{array}$ \\
\hline 1 & AMS-SD & bone collagen; extraction with alkali & $12270 \pm 50$ & $14285-14065$ & $14285-14065$ \\
\hline 2 & AMS-SD & bone collagen; extraction with alkali & $17670 \pm 60$ & $21550-21205$ & \multirow{3}{*}{ 21550-20995 } \\
\hline 2 & AMS-SD & bone collagen; extraction with alkali & $17530 \pm 60$ & $21360-20995$ & \\
\hline 2 & AMS-SD & charred material; acid/alkali/acid & $17640 \pm 60$ & $21510-21150$ & \\
\hline 3 & AMS-SD & bone collagen; extraction with alkali & $19460 \pm 70$ & $23605-23295$ & \multirow{2}{*}{$23940-23295$} \\
\hline 3 & AMS-SD & bone collagen; extraction with alkali & $19760 \pm 60$ & $23940-23650$ & \\
\hline 4 & AMS-SD & bone collagen; extraction with alkali & $19890 \pm 70$ & $24085-23790$ & \multirow{2}{*}{$24370-24065$} \\
\hline 4 & AMS-SD & bone collagen; extraction with alkali & $20150 \pm 70$ & $24370-24065$ & \\
\hline 5 & AMS-SD & bone collagen; extraction with alkali & $22140 \pm 80$ & $26525-26140$ & \multirow{2}{*}{$27405-26140$} \\
\hline 5 & AMS-SD & bone collagen; extraction with alkali & $22910 \pm 90$ & $27405-27130$ & \\
\hline 6 & AMS-SD & bone collagen; extraction with alkali & $23460 \pm 90$ & $27740-27525$ & $27740-27525$ \\
\hline 7 & AMS-SD & bone collagen; extraction with alkali & $25480 \pm 110$ & $29795-29340$ & $29795-29340$ \\
\hline 8 & AMS-SD & bone collagen; extraction with alkali & $26000 \pm 120$ & $30630-29875$ & \multirow{2}{*}{$37060-29875$} \\
\hline 8 & AMS-SD & bone collagen; extraction with alkali & $32640 \pm 220$ & $37060-36130$ & \\
\hline
\end{tabular}

from Layers 1-10 were sent to Beta Analytic Inc. (USA) for radiocarbon dating using the AMS-SD method (Table 1). Two samples failed to provide enough collagen to analyze, but the dating results of the remaining 14 samples are listed in Table 1. The fossil hominin tooth from Layer 2 could be securely assigned to 21 kya and the tooth from Layer 4 could be assigned to $\sim 24$ kya.

In this study, we provide a systematic metric and morphological study of the Laoya Cave teeth to explore how the Laoya hominins fit within the known dental morphological context of East Asian Late Pleistocene Homo. This is achieved using descriptive morphological observations, ge- ometric morphometric analysis, and micro-computed tomography (micro-CT). The Laoya Cave $\mathrm{dm}^{2}$ (LYC2) is only partially preserved, so this study will focus mainly on the $\mathrm{M}_{3}$ (LYC1).

\section{Materials and Methods}

The permanent molar (LYC1) was classified as an $\mathrm{M}_{3}$ rather than an $\mathrm{M}_{2}$ for two reasons: (i) the geometry of the crown outline shape (see Results); and (ii) the presence of a mesial interproximal wear facet and the absence of a distal facet.

Due to its relatively recent Late Pleistocene age ( 24 kya), 
Table 2. Comparative specimens used in the present study

\begin{tabular}{|c|c|c|c|c|}
\hline & & $n$ & Localities & Sources (metrics) \\
\hline \multicolumn{2}{|c|}{$\begin{array}{l}\text { East Asian Early/Middle } \\
\text { Pleistocene }\end{array}$} & 26 & Lantian, Hexian, Sangiran, Zhoukoudian & $\begin{array}{l}\text { Tobias and von Koenigswald, 1964; Grine } \\
\text { and Franzen, 1994; Kaifu et al., 2005; } \\
\text { Zanolli, } 2013\end{array}$ \\
\hline \multicolumn{2}{|l|}{ Neanderthal } & 48 & $\begin{array}{l}\text { Amud, Arcy Hyene, Arcy Grotte Renne, Arcy Sur Cure } \\
\text { (Mousterian), Ehringsdorf, Genay (Côte d'Or), Hortus, } \\
\text { Krapina, La Quina, Ochoz, Petit Puymoyen, Regourdou, } \\
\text { Shanidar, Spy, St. Césaire, Subalyuk, Tabun, Vindija }\end{array}$ & Milford Wolpoff, personal communication \\
\hline \multirow{2}{*}{$\begin{array}{l}\text { Recent } \\
\quad \text { H. sapiens }\end{array}$} & Africa & 40 & South Africa & \\
\hline & East Asia & 107 & $\begin{array}{l}\text { Xichuan (Henan Province), Yunxian, Danjiangkou, } \\
\text { Xiangyang, and Fangxian (Hubei Province) }\end{array}$ & This study \\
\hline \multirow{4}{*}{$\begin{array}{l}\text { Fossil } \\
\quad \text { H. sapiens }\end{array}$} & Africa & 2 & Klasies River mouth & Rightmire and Deacon, 1991 \\
\hline & West Asia & 10 & Qafzeh, Skhul & Milford Wolpoff, personal communication \\
\hline & East Asia & 20 & $\begin{array}{l}\text { Baojiyan, Chuandong, Daoxian, Fusui Nanshan, } \\
\text { Huanglong Cave, Huli Cave, Jimuyan, Longlin, } \\
\text { Maludong, Tianyuan Cave, Tubo, Zhiren Cave }\end{array}$ & $\begin{array}{l}\text { Wang et al., 1982; Huang, 1989; Wang and } \\
\text { Mo, 2004; Liu et al., 2010a, b; Wang et al., } \\
\text { 2011; Liu et al., 2015; }\end{array}$ \\
\hline & Europe & 23 & $\begin{array}{l}\text { Abri Pataud, Combe Capelle, Dolní Věstonice, Isturitz, } \\
\text { Le Rois, Mladeč, Pavlov, Predmostí, SG-LR }\end{array}$ & Milford Wolpoff, personal communication \\
\hline
\end{tabular}

* Sangiran 8, 21, 22, Sangiran NG9107.2

the Laoya Cave $\mathrm{M}_{3}$ (LYC1) will be compared to several hominin groups: (i) Late Pleistocene hominins (Neanderthals and fossil $H$. sapiens from around the world); (ii) chronologically earlier fossil hominins from the same geographical area (East Asian Early/Middle Pleistocene hominins); and (iii) recent East Asian and African H. sapiens. The recent East Asian $H$. sapiens sample comes from archaeological sites in central China, spanning the Neolithic to the Ming-Qing Dynasty. The recent African H. sapiens samples were obtained from the Raymond Dart Collection of Human Skeletons housed at the University of the Witwatersrand. Comparisons from other sources will be made throughout the text, particularly from Martinón-Torres et al. (2012). For detailed information of the comparative specimens (both $\mathrm{M}_{2}$ and $\mathrm{M}_{3}$ ), see Table 2. For details of the specimens included in the geometric morphometric analysis, see SI Table 1.

\section{Morphological traits and metrics}

All morphological descriptions, scoring, and comparisons were performed following the Arizona State University Dental Anthropology System (ASUDAS) (Turner et al., 1991) and the revised ASUDAS described in MartinónTorres et al. (2012). Mesiodistal (MD) and buccolingual (BL) dimensions of the crown were measured with standard sliding calipers and recorded to the nearest $0.1 \mathrm{~mm}$, following the methods of Wolpoff (1971). Two box-plots (MD and $\mathrm{BL}$, respectively) were used to display the metric variation among different groups. Additionally, the combination of non-metric traits expressed by each individual tooth in the sample was explored and compared to that of LYC1. A cluster analysis was also performed to compare the non-metric traits of LYC1 to individuals from other taxonomic groups.

\section{Geometric morphometric analysis}

Geometric morphometric (GM) analysis was performed on standardized occlusal surface pictures of $\mathrm{M}_{2}$ and $\mathrm{M}_{3}$ to examine the crown outline shape for two reasons: first, to classify the permanent molar (LYC1) as either $\mathrm{M}_{2}$ or $\mathrm{M}_{3}$ based on its outline shape; and second, to compare LYC1's shape to the other comparative specimens (Figure 2). The camera lens was oriented orthogonally to the plane formed by each tooth's cemento-enamel junction (CEJ) to standardize the pictures. When both antimeres were present, the left was photographed. When an individual was only represented by a right $\mathrm{M}_{2}$ or $\mathrm{M}_{3}$, the photograph was mirror-imaged in Adobe Photoshop ${ }^{\circledR}$ so it could be compared to the left $\mathrm{M}_{2} \mathrm{~S}$ and $\mathrm{M}_{3} \mathrm{~s}$. Two landmarks (green circles on Figure 2) representing the intersection points of the mesiobuccal and the lingual occlusal grooves with the crown outline (referred to as Type 1 in Bookstein (1991)) were defined. The outlines of the trigonid and talonid were each divided into 20 equidistant segments using the TpsDig2 program (Rohlf, 1998a). The dividing points were treated as semi-landmarks (blue squares on Figure 2). Overall, two landmarks and 38 semi-landmarks were defined along the $\mathrm{M}_{2}$ or $\mathrm{M}_{3}$ crown outline (Figure 2). The TpsDig2 program (Rohlf, 1998a) was used to digitize landmarks and semi-landmarks. The TpsRelw program (Rohlf, 1998b) was employed to superimpose the raw coordinate data and the relative warp analysis (or principal component analysis) of shape variables.

The first 10 relative warp scores were used for Fisher linear discriminant function analyses and a standard crossvalidation was conducted in SPSS 20.0. This step allows us to confirm the tooth category $\left(\mathrm{M}_{2}\right.$ or $\left.\mathrm{M}_{3}\right)$ for LYC1, and then to estimate the membership of LYC1 within other taxonomic groups based on the crown outline shape.

\section{Micro-computed tomography and the enamel-dentine junction}

High-resolution micro-CT was employed to virtually reconstruct the enamel-dentine (EDJ) (the dentine surface) of LYC1. LYC1 was scanned using a $225 \mathrm{kV}$ micro-CT scanner (designed by the Institute of High Energy Physics, Chinese Academy of Sciences, and housed at the Institute of Vertebrate Paleontology and Paleoanthropology, Chinese Academy of Sciences) equipped with a $1.0 \mathrm{~mm}$ aluminum filter 


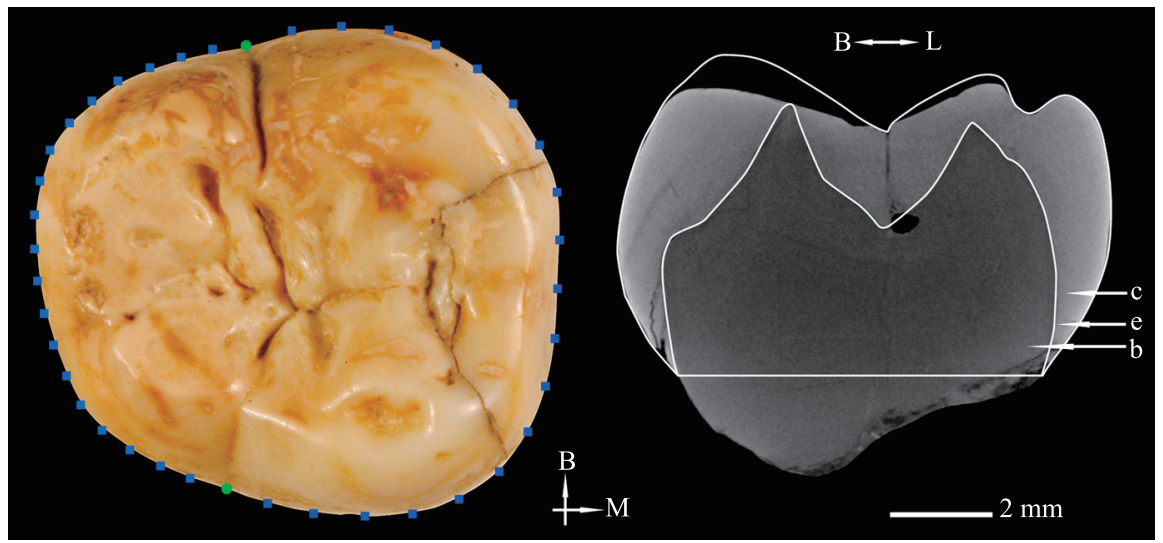

Figure 2. Left: the landmarks (circles) and semi-landmarks (squares) defined in the GM analysis of $\mathrm{M}_{3}$. Right: the mesial sectional plane of LYC1. B, buccal; L, lingual; M, mesial.

and using settings of $120 \mathrm{kV}, 100 \mu \mathrm{A}, 0.5^{\circ}$ angular increment per step, $360^{\circ}$ rotation, with an average of 4 frames. The final isometric voxel size was $15.68 \mu \mathrm{m}$. The images of raw projection generated from the scanner were converted to tomographic slices of RAW format with IVPP225kVCT Recon software. The size of each slice was $2048 \times 204 \overline{8}$ pixels. Multiple slices were put into VGstudio 2.2 and the empty spaces were removed to reduce the file size. The final data was saved as a RAW volume file, which was then imported into Mimics 17.0 to complete the segmentation of enamel and dentine and to visualize the EDJ surface. During the processes of enamel/dentine segmentation, 3D Livewire, single/multiple slice modification, and thresholding tools were employed.

In addition to the visual reconstruction of the EDJ surface, the average and relative enamel thickness of LYC1 were measured on a 2-D standardized section plane of the crown (Figure 2). The plane was prepared following Olejniczak (2006). First, a horizontal plane was fixed by three dentine horn tips (protoconid, metaconid, and hypoconid). Then, a sectional plane, perpendicular to the previous one and simultaneously cutting through the dentine horn tips of protoconid and metaconid, was defined. The area of the enamel cap (c) and dentine $(b)$ were measured as well as the length of the EDJ line $(e)$. The dentine area was defined as the area enclosed by the EDJ line and the shortest connecting line between the two most cervical points.

The occlusal wear was corrected for by virtually reconstructing the missing enamel portion by employing unworn occlusal surfaces as models and by considering the orientations of outer enamel and inner EDJ lines (Figure 2). The mesial plane section was defined in VGstudio 2.2, and then input into Image J for measurement of the enamel cap and the dentine area. Average enamel thickness (AET) was defined as $c / e$, and relative enamel thickness (RET) as 100 (AE$\mathrm{T} / \sqrt{ } b$ ). Both the values calculated using the corrected and uncorrected measurements were recorded. The LYC1 measurements were compared with those obtained by Olejniczak et al. (2008) and Smith et al. (2012). The validity of comparing data from different methods has been discussed in other works (Olejniczak et al., 2008; Smith et al., 2012).

The 3-D average and relative enamel thickness of LYC1 were also measured. The tooth was adjusted to approximate its anatomical position in VGStudio 2.2. Following the method in Olejniczak (2006), a plane (A) was defined along the cervix as the most apical position that contains a continuous ring of enamel. Another cervical plane (B) was defined as the position at the apex of the tooth, carrying the last tip of enamel. The plane separating the crown and root areas was located halfway between planes A and B. Volume (in $\mathrm{mm}^{3}$ ) and area (in $\mathrm{mm}^{2}$ ) measurements were recorded in the crown part following Kono (2004) and Olejniczak (2006): (i) the volume of the enamel cap (EVOL); (ii) the volume of coronal dentine (including the part of pulp cavity intruded into enamel cap) (DVOL); and (iii) the surface area of the EDJ surface (EDJESA). Average enamel thickness (in mm) (AET3D) was calculated as EVOL/EDJESA, and relative enamel thickness (RET3D) as AET3D $\times 100 / 3 \sqrt{ }$ DVOL (Kono, 2004; Olejniczak, 2006). Avizo 8.0 was used to visualize the distribution pattern of 3-D enamel thickness for LYC1.

\section{Results}

\section{Descriptions}

Only the protocone and a small portion of the lingual root are present on the $\mathrm{dm}^{2}$, LYC2 (Figure 3). The MD and BL measurements of the remaining part are 5.52 and $5.16 \mathrm{~mm}$, respectively. The occlusal wear is heavy, exposing a large band of dentine (grade 3 or 4 according to Molnar (1971)). There is no sign of Carabelli's cusp on the protocone. Due to the level of wear and broken nature of LYC2, it will not be analyzed extensively in this paper.

The LYC1 $\mathrm{M}_{3}$ crown is well preserved and while there is some wear (Figure 4), no dentine is exposed (grade 2 wear according to Molnar (1971)). Unfortunately, most of the root is missing. The mesial interproximal wear facet is oval and large and there is no distal interproximal wear facet. LYC1 has a trapezoidal crown outline with a narrowing talonid (Figure 4, Figure 5). All four main cusps (protoconid, metaconid, hypoconid, and entoconid) are present. There is no sign of a hypoconulid, C6, or $\mathrm{C} 7$. The protoconid and entoconid are connected so the main groove forms an ' $\mathrm{X}$ ' pattern (ASUDAS; grade 2 in Martinón-Torres et al. (2012)). 


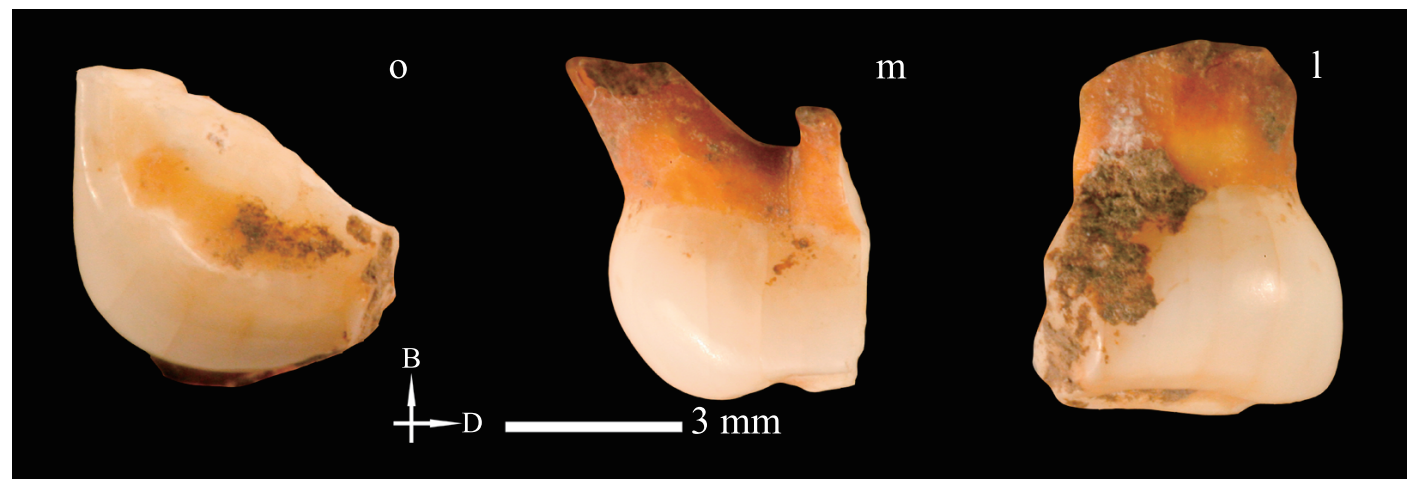

Figure 3. The $\mathrm{dm}^{2}$ from Laoya Cave (o, occlusal; m, mesial; 1, lingual; B, buccal; D, distal).

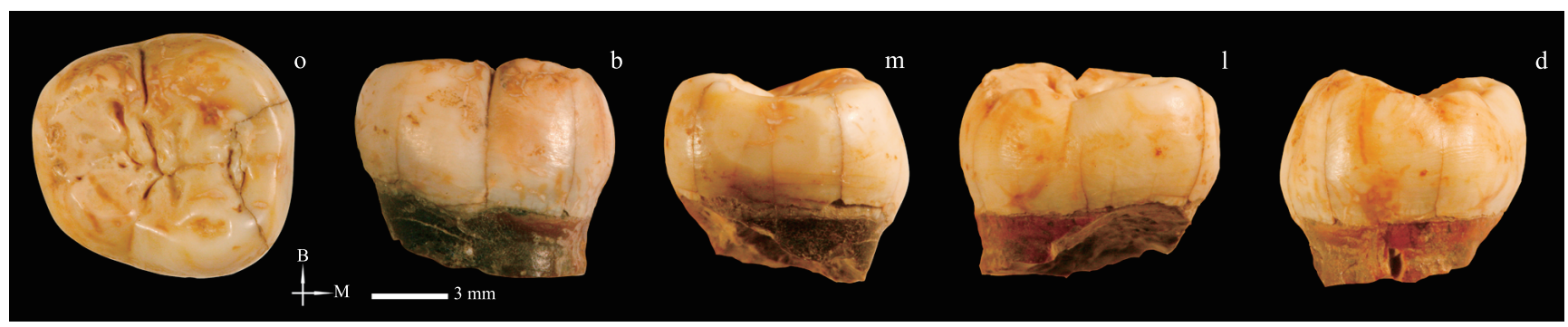

Figure 4. The $\mathrm{M}_{3}$ from Laoya Cave (o, occlusal; $\mathrm{b}$, buccal; $\mathrm{m}$, mesial; 1 , lingual; $\mathrm{d}$, distal).

A linear-like anterior fovea is present and well developed (ASUDAS grade 2). Distal to the anterior fovea is a middle trigonid crest (MTC) that is slightly notched by the mesial groove (Type 3 or 5 according to Korenhof (1982); Type A according to Martínez de Pinillos et al. (2014); grade 1 according to Martinón-Torres et al. (2012)). There is no distal trigonid crest (DTC) or deflecting wrinkle. The distal accessory ridge of the protoconid is present, as are both the mesial and distal accessory ridges of the hypoconid. A pit is present slightly lingual to the cusp tip of the metaconid (Figure 4, Figure 5). The buccal surface of the crown is featureless and does not include a protostylid. The buccal cervical line is slightly convex at the point where root bifurcation is most likely, and the enamel extension is grade 1 according to ASUDAS.

The occlusal surface of the EDJ is simple, without secondary grooves or ridges (Figure 5 II, III), except the distal accessory ridges of the protoconid and metaconid which are slightly elevated. The essential ridges of both protoconid and metaconid are well developed, but their connections are completely disrupted (no continuous MTC) (Grade 1 according to Bailey et al. (2011); Type 4 according to Martínez de Pinillos et al. (2014)). The dentine horn of the metaconid is accompanied by a shelf-like structure on its distolingual side, corresponding to the large pit on the enamel surface (Figure 5). On the buccal surface of the EDJ, there is a secondary groove originating from the mesial groove and outlining a triangle-like protostylid (grade 4 if ASUDAS was followed, although no protostylid appears on the enamel surface). Mesial to the protostylid, a dentine groove was formed by the elongation of the mesial marginal ridge into
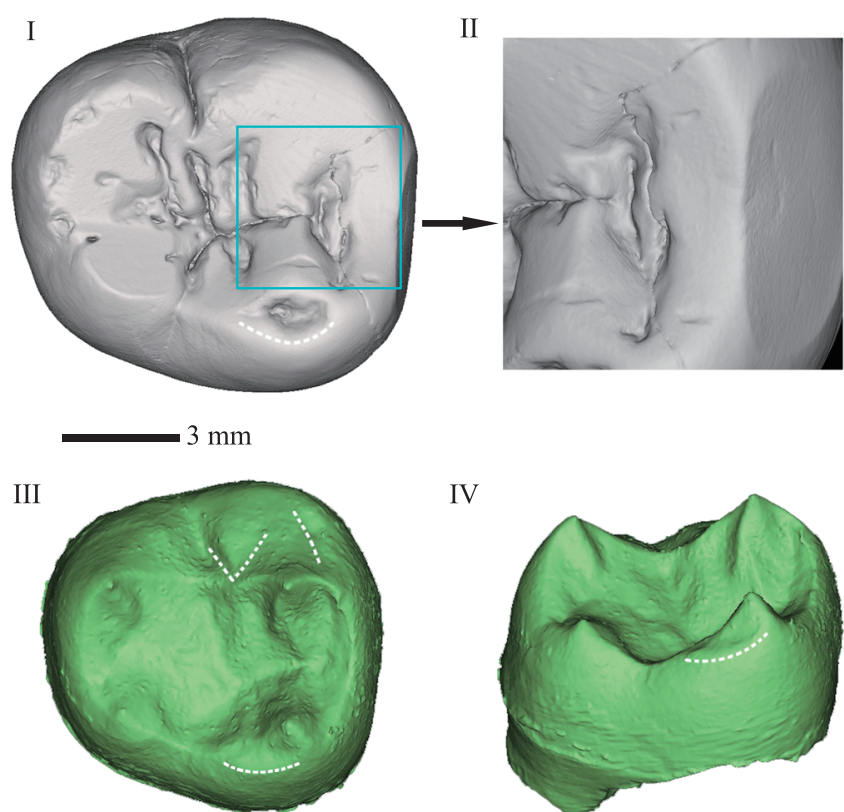

IV

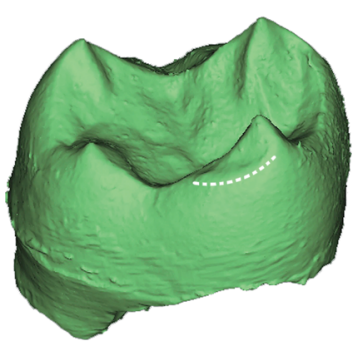

Figure 5. The visual reconstruction of the LYC1 outer enamel and EDJ surfaces reconstructed from micro-CT scanning. (I) Occlusal view of the outer enamel surface. The dotted line indicates the outline of the pit on the metaconid. (II) Enlarged view of the middle trigonid crest (MTC) area enclosed by the cyan rectangle in I; (III) Occlusal view of the EDJ surface. The dotted line points to the shelf-like structure on the metaconid. (IV) Buccal view of the EDJ surface. The dotted line indicates the dentine groove and the dotted triangle marks the protostylid. These images are not scaled. 
the buccal area.

The enamel cap area, calculated on the 2-D section of the LYC1, is $18.87 \mathrm{~mm}^{2}$; when the cap is restored to correct for the occlusal wear, the cap area is $20.91 \mathrm{~mm}^{2}$. The dentine area is $28.82 \mathrm{~mm}^{2}$ and the EDJ length is $17.78 \mathrm{~mm}$. The uncorrected 2-D average enamel thickness (AET2D) and relative enamel thickness (RET2D) are $1.06 \mathrm{~mm}$ and 19.74, respectively. The corrected values are $1.18 \mathrm{~mm}$ and 21.97 , respectively. The volume of the enamel cap (uncorrected) and dentine are $217.51 \mathrm{~mm}^{3}$ and $183.25 \mathrm{~mm}^{3}$, respectively. The area of the EDJ surface is $155.47 \mathrm{~mm}^{2}$. The uncorrected 3-D average enamel thickness (AET3D) and relative enamel thickness (RET3D) are $1.40 \mathrm{~mm}$ and 24.65 , respectively.

\section{Comparisons}

\section{Geometric morphometric analysis}

Geometric morphometric analysis of $\mathrm{M}_{2}$ versus $\mathrm{M}_{3}$ crown shape indicates that the first two relative warps (RW1 and RW2) account for $39.89 \%$ and $22.24 \%$ of the total shape variation in the crown outline (Figure 6). Although the $\mathrm{M}_{2}$ and $\mathrm{M}_{3}$ areas overlap, the $\mathrm{M}_{3}$ teeth are more displaced towards the negative-value extreme of both RW1 and RW2 axis. LYC1 is located near the lower left border of the $\mathrm{M}_{3} \mathrm{~s}$ in the graphics, and relatively far away from the area of $\mathrm{M}_{2} \mathrm{~s}$. To further support the classification of LYC1 as $\mathrm{M}_{3}$, discriminant function analysis (cross-validation) also clusters it with $\mathrm{M}_{3} \mathrm{~s}$ in $100 \%$ of cases (Figure 6).

Geometric morphometric analysis of $\mathrm{M}_{3}$ crown shape (Figure 7) indicates that the first three relative warps (RW1, RW2, and RW3) account for $39.89 \%, 22.24 \%$, and $15.85 \%$, respectively, of the total shape variation of the crown outline. Specimens at the positive-value extreme of RW1 tend to have a more symmetrical crown contour with a talonid that is reduced in both MD and BL directions, and the mesial part of the crown is markedly wider than the distal end. In contrast, specimens that fall along the negative end of RW1 tend to have an enlarged talonid in both MD and BL directions. Teeth at both the positive and negative extents of RW2 have an asymmetrical crown outline, with the talonid shifted in lingual and buccal direction related to the trigonid, respectively. Specimens at the negative-value extreme of RW2 tend to have a mesiodistally elongated crown related to those at other end. Compared to those in the negative-value extreme of RW3, teeth plotted against the positive-value end tend to have mesiodistally elongated crowns (SI Figure 1).

Although ranges overlap, there are still some distribution tendencies that can be traced (Figure 7). Most specimens of the East Asian Early/Middle Pleistocene hominins tend to distribute along the positive-value half of RW1, while the Neanderthals mainly plot along the negative-value half of RW1. Most specimens of fossil H. sapiens are distributed along the negative-value half of the RW3. The LYC1 plots in the far right side of the graph. Although LYC1 plots outside the distribution area of Neanderthals and $H$. sapiens along the RW1, it completely overlaps with them on the RW2 and RW3 axes.

Based on the discriminant functional analysis of the $\mathrm{M}_{3}$ crown outline shape (SI Table 2), 29.7\% of cross-validated grouped cases were correctly classified. When cross-validated, LYC1 falls into the recent $H$. sapiens group.

\section{Metrics}

The MD and BL dimensions of $\mathrm{LYCl}$ are $11.0 \mathrm{~mm}$ and $10.1 \mathrm{~mm}$, respectively. The MD measurement of LYC1 is at the upper limit of the first quartile for both East Asian Early/Middle Pleistocene hominins and West Asian fossil $H$. sapiens (Figure 8). It falls into the lower quartile of Neanderthals, the mid-range of fossil $\mathrm{H}$. sapiens from Africa and Europe and recent East Asian H. sapiens, and the upper quartile of East Asian fossil $\mathrm{H}$. sapiens. In the BL dimension,
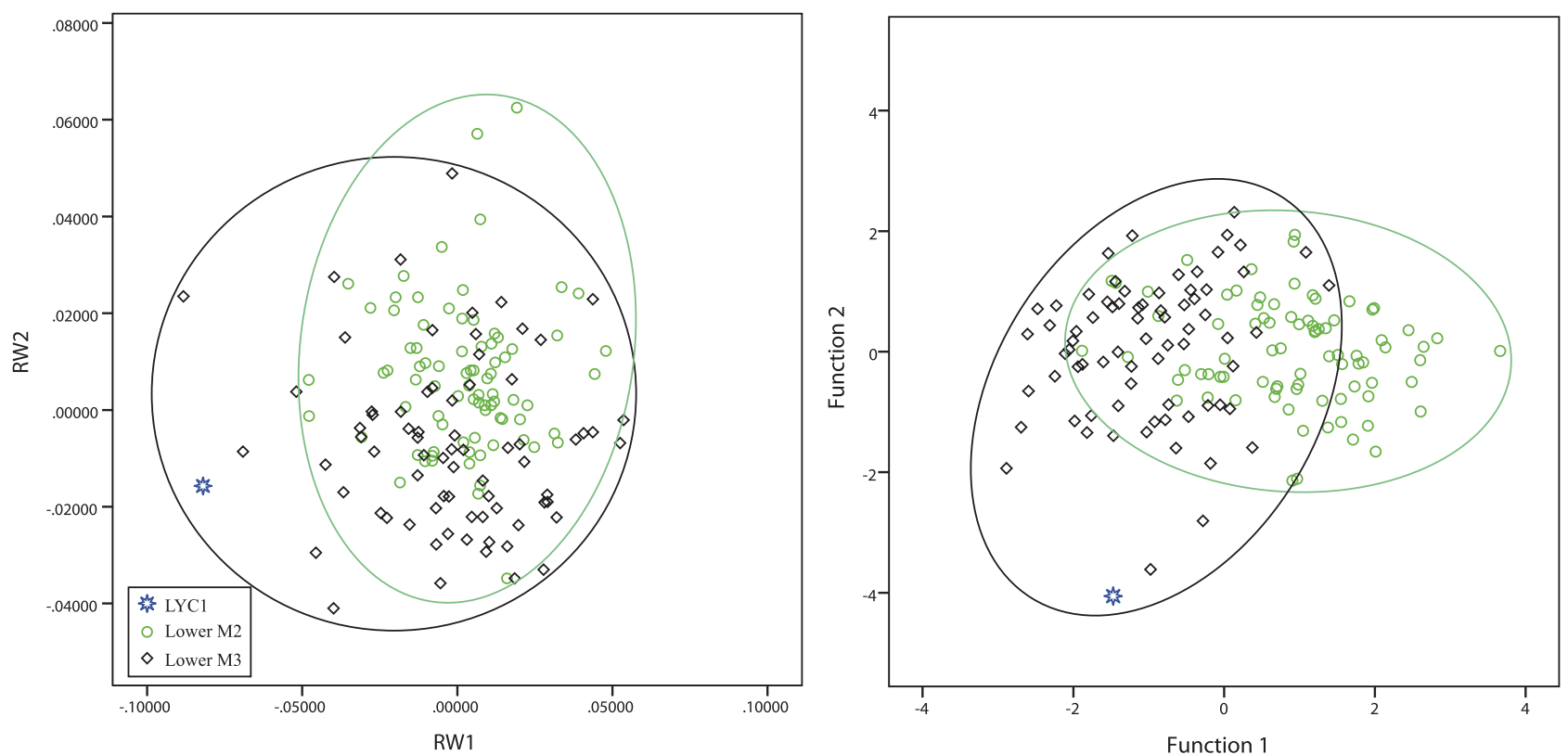

Figure 6. Left: geometric morphometric analysis of $\mathrm{M}_{2}$ and $\mathrm{M}_{3}$. Right: discriminant function analysis of $\mathrm{LYC1}, \mathrm{M}_{2}$, and $\mathrm{M}_{3}$. 


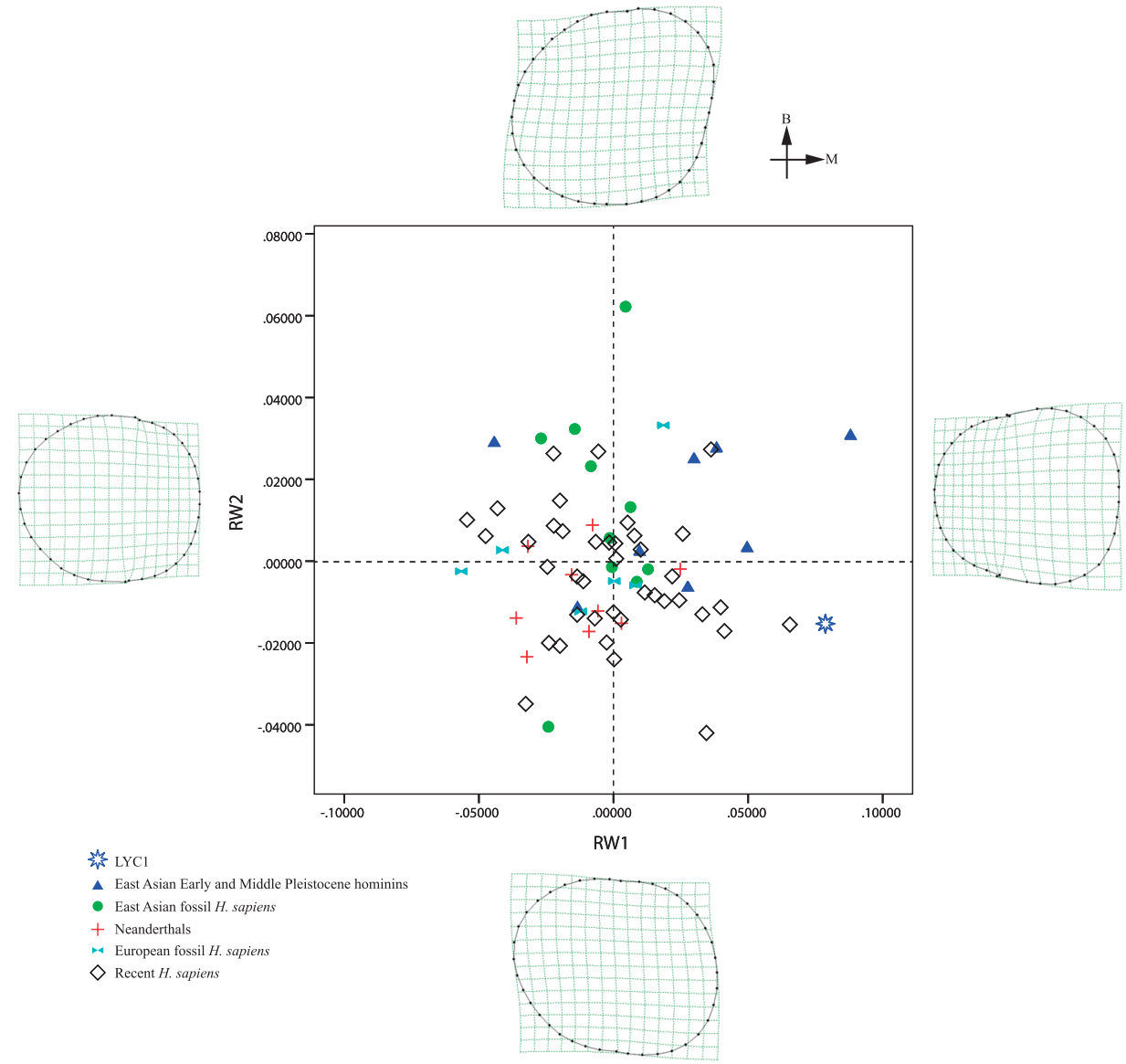

Figure 7. Geometric morphometric analysis of $\mathrm{M}_{3}$, with the RW1 and RW2 being shown (TPS grids correspond to the positive-value or negative-value extremes of the RW axis). B, buccal; M, mesial.
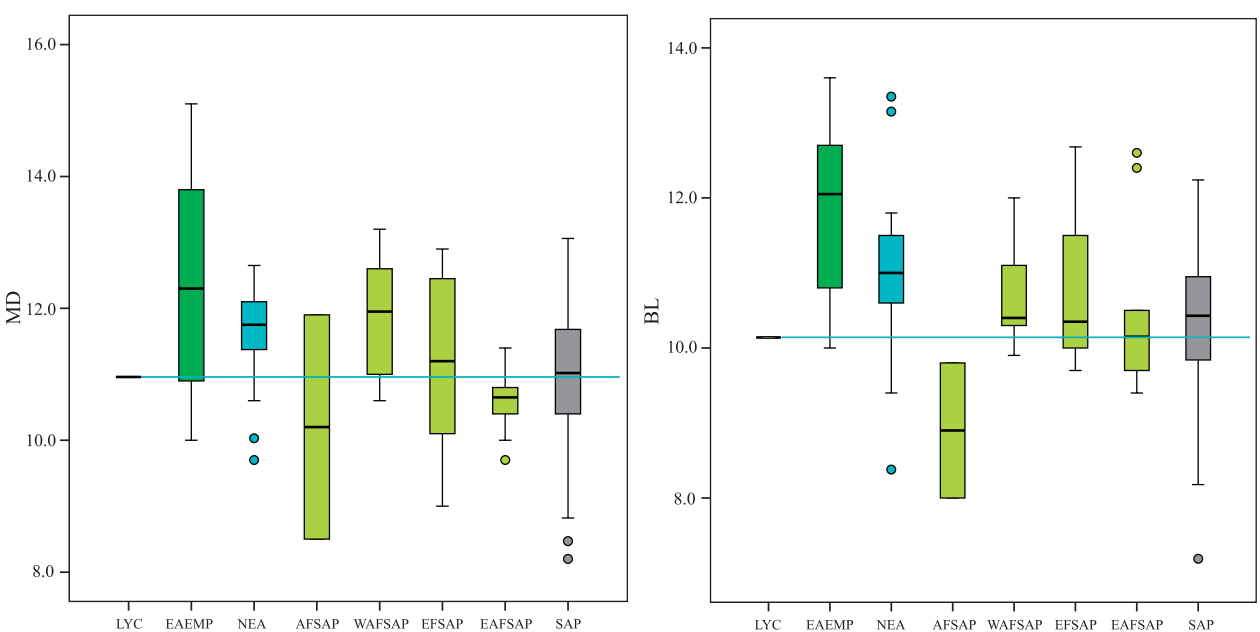

Figure 8. Box-plot of the crown sizes of LYC1 and the comparative samples. LYC, Laoya Cave; EAEMP, East Asian Early and Middle Pleistocene hominins; NEA, Neanderthals; AFSAP, African fossil $H$. sapiens; WAFSAP, West Asian fossil $H$. sapiens; EFSAP, European fossil $H$. sapiens; EAFSAP, East Asian fossil H. sapiens; SAP, recent H. sapiens.

the LYC1 measurement only exceeds the range of African fossil $H$. sapiens. It falls below the median value for every other group, and only falls within the mid-range of recent East Asian $\mathrm{H}$. sapiens and fossil $\mathrm{H}$. sapiens from Europe and East Asia.

\section{Morphology}

Table 3 shows specific frequencies of morphological traits organized by group, geography, and grade; the gray highlighted rows represent the grade characteristic for LYC1.

Early/Middle Pleistocene East Asian hominins and Nean- 
derthals typically have a hypoconulid, usually grade 3 or 4; the absence of this cusp in LYC1 is quite rare (present study; Martinón-Torres et al., 2012). Indeed, the presence of a grade 3-4 hypoconulid is common in East Asia across both fossil and recent $H$. sapiens. However, for fossil and recent H. sapiens outside of East Asia published by MartinónTorres et al. (2012), the absence of a hypoconulid is more frequent $(33.3 \%$ and $50.0 \%)$.

LYC1 lacks both a C6 and C7 cusp. The presence and size of these two cusps varies greatly in different groups. C6s and C7s are most frequently found in Early/Middle Pleistocene East Asian hominins. The absence of a C7 increases from $62.5 \%$ to $90.0 \%$ between fossil and recent East Asian $H$. sapiens.

Although notched by the central groove, an MTC is present in LYC1 (grade 1 in Martinón-Torres et al. (2012), see the description for the grade of this trait according to other scoring system). The presence of a MTC is quite rare in H. sapiens, with $89.9-100 \%$ of the reported fossil and recent H. sapiens missing an MTC (grade 0) (Table 3) (present study; Martinón-Torres et al., 2012). However, more than $50 \%$ of Neanderthal individuals had an MTC.

It is noteworthy that the MTC structure is present on the outer enamel surface but absent on the EDJ surface of LYC1 (Figure 5). Previous studies have detected this discrepancy (Bailey et al., 2011; Martínez de Pinillos et al., 2014). Martínez de Pinillos et al. (2014) noticed that the way in which MTC is expressed on the dentine surface is more complicated than on the enamel surface. Bailey et al. (2011) pointed out that the degree to which MTC expression corresponds between the enamel and dentine surfaces was lower in $H$. sapiens than in Neanderthals, and the authors proposed that the thicker enamel found in $H$. sapiens might be the cause. Bailey et al. (2011) also states that when the discrepancy between enamel and dentine MTC expression occurs, the EDJ always has a higher degree of MTC expression.

The smooth EDJ surface of LYC1 is different from that of Hexian H. erectus PA834-2 (Xing et al., 2014). The essential crests of PA834-2 are more elevated or developed than in LYC1. In addition, LYC1 does not have as many accessory ridges as in PA834-2. The NG92.3 and NG0802.2 of Java H. erectus display an EDJ surface as simple as that of LYC1 (Zanolli, 2015). However, the EDJ surface of the other $\mathrm{M}_{3}$ (NG9107.2) is slightly more complicated due to the development of several accessory ridges (Zanolli, 2015).

The frequency of non-Y pattern grooves increases through hominin history. The ' $\mathrm{X}$ ' pattern, as in LYC1, did not become very common until relatively recently (MartinónTorres et al., 2012; Xing et al., 2014). Only 4 out of 12 specimens of Early/Middle Pleistocene East Asian hominins exhibit the ' $\mathrm{X}$ ' pattern. In comparison, the frequency of the ' $\mathrm{X}$ ' pattern in recent East Asian H. sapiens is $90.0 \%$.

The East Asian Early/Middle Pleistocene hominins generally express grades 0-2 (ASUDAS) of enamel extension in the $\mathrm{M}_{3}$. LYC1 falls into this range, with grade 1 enamel extension. In contrast, about $54 \%$ of recent East Asian $H$. sapiens specimens exhibited grade 3 enamel extension. In some cases, the high degree of enamel extension forms a line of enamel extending all the way to the bifurcation point of the root/radical. This linear type of enamel extension has been reported in East Asian early Late Pleistocene fossil H. sapiens from Daoxian Fuyan Cave and Huanglong Cave (Liu et

Table 3. Frequencies of the degrees of expression of $\mathrm{M}_{3}$ 's main morphological traits

\begin{tabular}{|c|c|c|c|c|c|c|c|}
\hline & \multirow{2}{*}{ Grade } & \multirow{2}{*}{$\begin{array}{c}\text { Early/Middle } \\
\text { Pleistocene }\end{array}$} & \multirow{2}{*}{$\begin{array}{c}\text { Neanderthal } \\
\text { Europe and West } \\
\text { Asia* }\end{array}$} & \multicolumn{2}{|c|}{ Fossil H. sapiens } & \multicolumn{2}{|c|}{ Recent $H$. sapiens } \\
\hline & & & & $\begin{array}{l}\text { West Asia and } \\
\text { Europe* }\end{array}$ & East Asia & $\begin{array}{l}\text { Africa and } \\
\text { Europe* }\end{array}$ & East Asia \\
\hline \multirow{6}{*}{$\begin{array}{l}\text { Hypoconulid } \\
\text { size }\end{array}$} & 0 & —** & $2(12.5 \%)$ & $6(33.3 \%)$ & - & $63(50.0 \%)$ & $5 \quad(7.1 \%)$ \\
\hline & 1 & - & - & $1(5.6 \%)$ & - & $3(2.4 \%)$ & $1 \quad(1.4 \%)$ \\
\hline & 2 & $1 \quad(9.1 \%)$ & $1 \quad(6.3 \%)$ & $2(11.1 \%)$ & - & $14(11.1 \%)$ & $4 \quad(5.7 \%)$ \\
\hline & 3 & $3(27.3 \%)$ & $7(43.8 \%)$ & $6(33.3 \%)$ & $3(37.5 \%)$ & $17(13.5 \%)$ & $14(20.0 \%)$ \\
\hline & 4 & $6(54.5 \%)$ & $5(31.3 \%)$ & $2(11.1 \%)$ & $3(37.5 \%)$ & $17(13.5 \%)$ & $24(34.3 \%)$ \\
\hline & 5 & $1(9.1 \%)$ & $1(6.3 \%)$ & $1(5.6 \%)$ & $2(25.0 \%)$ & $12(9.5 \%)$ & $22(31.4 \%)$ \\
\hline \multirow{4}{*}{ C6 size } & 0 & $2(22.2 \%)$ & $5(33.3 \%)$ & $12(66.7 \%)$ & $3(50.0 \%)$ & $94(77.7 \%)$ & $40(57.1 \%)$ \\
\hline & 1 & - & $1(6.7 \%)$ & - & - & $9(7.4 \%)$ & $2(2.9 \%)$ \\
\hline & 2 & $4(44.4 \%)$ & $4(26.7 \%)$ & $4(22.2 \%)$ & $2(33.3 \%)$ & $11 \quad(9.1 \%)$ & $9(12.9 \%)$ \\
\hline & 3 & $3(33.3 \%)$ & $5(33.3 \%)$ & $2(11.1 \%)$ & $1 \quad(16.7 \%)$ & $7 \quad(5.8 \%)$ & $19(27.1 \%)$ \\
\hline \multirow{5}{*}{ C7 size } & 0 & - & $8(53.3 \%)$ & $13(76.5 \%)$ & $5 \quad(62.5 \%)$ & $98(79.0 \%)$ & $63(90.0 \%)$ \\
\hline & 1 & - & $1(6.7 \%)$ & $1(5.9 \%)$ & - & $10(8.1 \%)$ & $2(2.9 \%)$ \\
\hline & 2 & $2(18.2 \%)$ & $3(20.0 \%)$ & $3(17.6 \%)$ & - & $6(4.8 \%)$ & $1 \quad(1.4 \%)$ \\
\hline & 3 & $5(45.5 \%)$ & $1 \quad(6.7 \%)$ & - & $1 \quad(12.5 \%)$ & $7 \quad(5.6 \%)$ & $2(2.9 \%)$ \\
\hline & 4 & $4(36.4 \%)$ & $2(13.3 \%)$ & - & $2(25.0 \%)$ & $3(2.4 \%)$ & $2(2.9 \%)$ \\
\hline \multirow{3}{*}{$\begin{array}{l}\text { Middle } \\
\text { trigonid crest }\end{array}$} & 0 & $9(75.0 \%)$ & $1(5.9 \%)$ & $14(93.3 \%)$ & $8(100.0 \%)$ & $107(89.9 \%)$ & $69(98.6 \%)$ \\
\hline & 1 & $1(8.3 \%)$ & $4(23.5 \%)$ & $1(6.7 \%)$ & - & $12(10.1 \%)$ & $1(1.4 \%)$ \\
\hline & 2 & $2(16.7 \%)$ & $12(70.6 \%)$ & - & - & - & - \\
\hline \multirow{2}{*}{$\begin{array}{l}\text { Groove } \\
\text { pattern }\end{array}$} & 1 & $8(33.3 \%)$ & $9(60.0 \%)$ & $2(14.3 \%)$ & $2(22.2 \%)$ & $21(19.1 \%)$ & $7(10.0 \%)$ \\
\hline & 2 & $4(66.7 \%)$ & $6(40.0 \%)$ & $12(85.7 \%)$ & $7 \quad(77.8 \%)$ & $89(80.9 \%)$ & $63(90.0 \%)$ \\
\hline
\end{tabular}

* Martinón-Torres et al. (2012).

** '_-' means ' 0 '. 
al., 2010b, 2015), but it is not present in the LYC1 $\mathrm{M}_{3}$.

When all five traits are considered, no other specimen, extant or extinct, matches the pattern of scores expressed by LYC1 (SI Table 3, SI Table 4). Although no individuals match the suite of all five traits presented in LYC1, three recent Chinese modern humans (SI Table 4) and a Homo floresiensis individual (LB6/1) match four of LYC1's scores, but they all lack an MTC (SI Table 4; see Figure 1 in Kaifu et al. (2015)). Aside from LB6/1, no fossil specimen includes this combination of traits (SI Table 3, SI Table 4). Cluster analysis shows that LYC1 clusters with six recent Chinese modern humans and separates from the rest of the individuals in the study (SI Table 4, SI Figure 2).

It is primarily the lack of a hypoconulid and the presence of an MTC that distinguishes LYC1 from all of the other specimens in this sample; no other tooth has that combination of traits (SI Table 4). The combination of a lack of C6, $\mathrm{C} 7$, and a non-Y pattern of grove arrangement is fairly common in our sample (33/96 individuals; 30/33 are recent Chinese modern humans).

\section{Enamel thickness}

Once the occlusal wear was corrected for by virtually reconstructing the enamel cap (Figure 2, see Methods), the corrected AET2D value for LYC1 is $1.18 \mathrm{~mm}$. This value is slightly above the upper limit of Neanderthals, but falls into the range of fossil and recent $H$. sapiens (Table 4). For RET2D, both corrected and uncorrected values of LYC1 are greater than for Neanderthals. The corrected RET2D of LYC1 falls slightly above the range for fossil $H$. sapiens and is well within the range of recent $H$. sapiens. Neanderthal $\mathrm{M}_{3}$ s generally have thinner enamel than $H$. sapiens, though some overlapping exits in both AET2D and RET2D (Table 4).

The AET3D of LYC1 (Table 5) falls within the range of variation for both Neanderthals and recent $H$. sapiens (values from Pan et al. (2016)). The value of LYC1 is higher than the mean value of Neanderthals provided in Olejniczak et al. (2008). In the RET3D, the value of LYC1 is slightly higher than the mean of Neanderthals and recent $H$. sapiens, and exceeds the upper limit of the range of variation.

\section{Distribution of 3-D enamel thickness}

Although the occlusal surface of LYC1 is slightly worn (no dentine is exposed), the pattern of 3-D enamel thickness distribution could still be observed (Figure 9). Overall, the thickest enamel falls around the buccal groove in the occlusal aspect of the buccal surface. $\mathrm{M}_{3} \mathrm{~s}$ of recent modern humans show a similar pattern (see also SI Figure 4 in Pan et al. (2016)), with the buccal surface being thicker than the lingual aspect. Typically, the occlusal third of the hypoconid's buccal surface has thick, evenly distributed enamel in recent $H$. sapiens; however, it is the mesial aspect of the hypoconid that shows the thicker enamel in LYC1. Despite this difference, we should be cautious with interpreting it until more data is available. $\mathrm{A} \mathrm{M}_{3}$ from Hexian $H$. erectus (PA831) (unpublished data) and a $\mathrm{M}_{3}$ from Java (NG0802.2) (see Figure 2 in Zanolli (2015)) are similar to that of recent $H$. sapiens in the distribution pattern of 3-D enamel thickness.

\section{Discussion}

$\mathrm{M}_{3}$ morphology is highly variable among the recent $H$. sapiens, and this tooth category has generally not been included in previous investigations of population history (e.g. Turner, 1987; Matsumura and Oxenham, 2014). However, a suite of $\mathrm{M}_{3}$ characteristics has been identified as taxonomically and phylogenetically informative, with varying reliability among different taxa (Olejniczak et al., 2008; Bailey et al., 2011; Martinón-Torres et al., 2012; Smith et al., 2012; Martínez de Pinillos et al., 2014; Gómez-Robles et al., 2015). Additionally, principal component, canonical variance, and corresponding discriminant function analyses accurately separate $\mathrm{M}_{2}$ and $\mathrm{M}_{3} \mathrm{~s}$ in this study. These characteristics were considered in the present study in order to characterize the Laoya Cave permanent molar, and to document the morphological variation among the East Asian

Table 4. Comparisons of AET2D (2-D average enamel thickness) and RET2D (2-D relative enamel thickness) between LYC1 and other fossil hominins and recent $H$. sapiens (parentheses indicate the range when more than one specimen was reported).

\begin{tabular}{|c|c|c|c|c|c|c|}
\hline \multirow[b]{2}{*}{ Source } & \multicolumn{2}{|c|}{ LYC1 } & \multicolumn{2}{|c|}{ Neanderthal } & \multirow{2}{*}{$\begin{array}{c}\text { Fossil H. sapiens } \\
\text { Smith et al. } \\
(2012)\end{array}$} & \multirow{2}{*}{$\begin{array}{c}\text { Recent } H \text {. sapiens } \\
\text { Smith et al. } \\
(2012)\end{array}$} \\
\hline & $\begin{array}{l}\text { This study } \\
\text { corrected }\end{array}$ & $\begin{array}{l}\text { This study } \\
\text { uncorrected }\end{array}$ & $\begin{array}{c}\text { Smith et al. } \\
(2012)\end{array}$ & $\begin{array}{c}\text { Olejniczak et al. } \\
(2008)\end{array}$ & & \\
\hline$n$ & 1 & 1 & 6 & 8 & 2 & 45 \\
\hline $\begin{array}{l}\text { AET } \\
(\mathrm{mm})\end{array}$ & 1.18 & 1.06 & $\begin{array}{c}1.01 \\
(0.91-1.16)\end{array}$ & 0.99 & $\begin{array}{c}1.28 \\
(1.15-1.41)\end{array}$ & $\begin{array}{c}1.25 \\
(0.98-1.74)\end{array}$ \\
\hline RET & 21.97 & 19.74 & $\begin{array}{c}16.8 \\
(14.3-18.3)\end{array}$ & 16.55 & $\begin{array}{c}20.5 \\
(19.2-21.9)\end{array}$ & $\begin{array}{c}21.7 \\
(17.2-31.8)\end{array}$ \\
\hline
\end{tabular}

Table 5. Comparisons of AET3D (3-D average enamel thickness) and RET3D (3-D relative enamel thickness) between LYC1 and other fossil hominins and recent $H$. sapiens (parentheses indicate the range when more than one specimen was reported).

\begin{tabular}{|c|c|c|c|c|c|}
\hline \multirow{2}{*}{ Source } & \multirow{2}{*}{$\begin{array}{c}\text { LYC1 } \\
\text { This study uncorrected }\end{array}$} & \multicolumn{2}{|c|}{ Neanderthal } & \multicolumn{2}{|c|}{ Recent $H$. sapiens } \\
\hline & & Pan et al. (2016) & Olejniczak et al. (2008) & Pan et al. (2016) & Olejniczak et al. (2008) \\
\hline$n$ & 1 & 5 & 6 & 4 & 9 \\
\hline $\mathrm{AET}(\mathrm{mm})$ & 1.40 & $1.38(1.24-1.54)$ & 1.06 & $1.38(1.20-1.47)$ & 1.45 \\
\hline RET & 24.65 & $21.24(19.11-23.73)$ & 15.43 & $22.06(20.52-23.74)$ & 23.79 \\
\hline
\end{tabular}



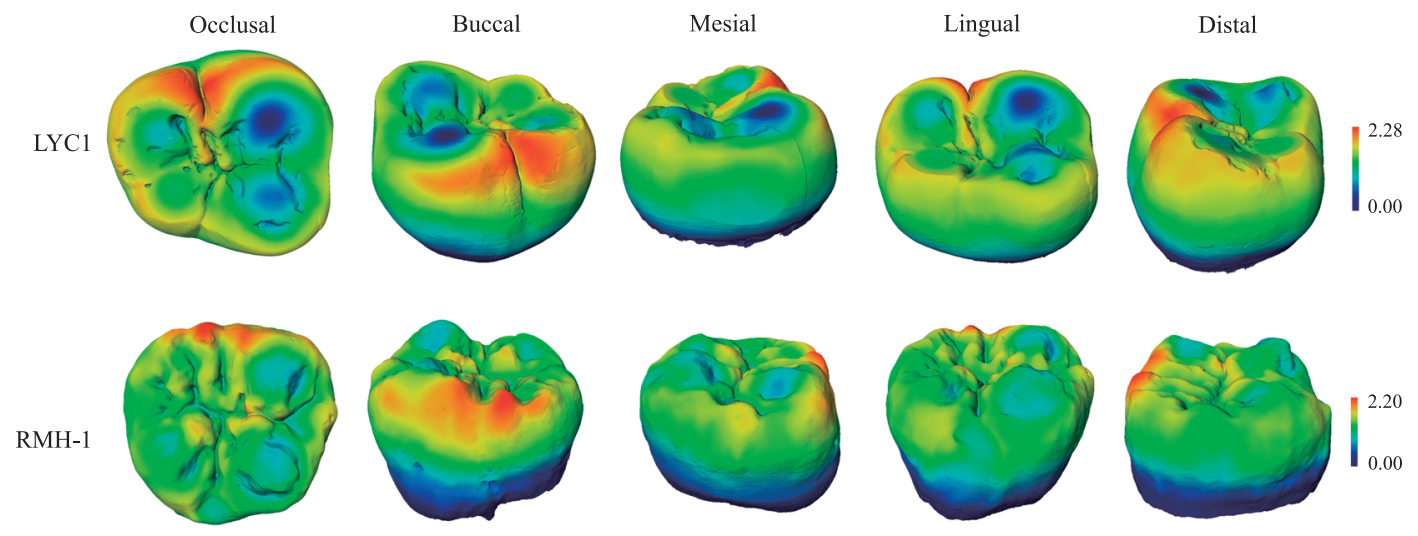

RMH-2
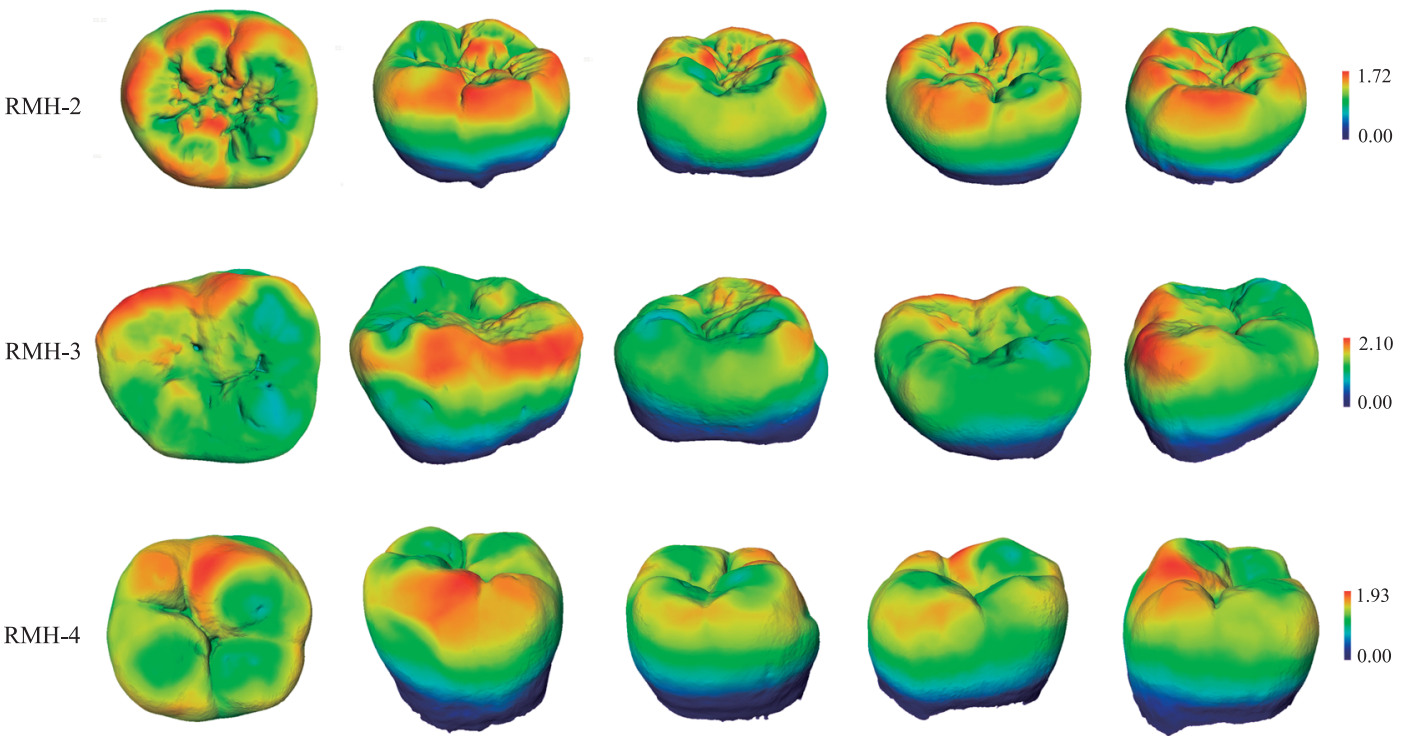

Figure 9. The distribution pattern of 3-D enamel thickness in LYC1 and four other specimens of recent H. sapiens: RMH-1, Yunxian M101; RMH-2, Xichuan M144; RMH-3, Yunxian M263; RMH-4, Yunxian M22. The images are not scaled.

\section{fossil H. sapiens.}

Given its age and location, the expectation was that LYC1 should have morphological traits most typical of recent H. sapiens. As expected, the crown dimensions of LYC1 are fairly small and fall most consistently within the ranges of other Asian and European fossil and recent $H$. sapiens. Similarly, the 2-D relatively thick average and relative enamel thickness values established for LYC1 fall more soundly within the $H$. sapiens range than the Neanderthal range. The discriminant function analysis of the crown outline shape variables and dental non-metrics all assign LYC1 into groups of recent $H$. sapiens.

However, the 3-D enamel thickness displayed a less clear situation based on the comparative data from different sources. Our study also revealed that the variation in recent $H$. sapiens established by our East Asian sample differs slightly from the known modern human variation established by Martinón-Torres et al. (2012). Surprisingly, LYC1 does not always follow the morphological suite of features established for the recent East Asian H. sapiens from China. LYC1 exhibits a combination of dental traits (no hypoconu- lid, C6, C7, and ' $\mathrm{X}$ ' groove pattern) that could only be identified in three recent Chinese $H$. sapiens individuals. No comparative specimens matched the LYC1 scores for all five non-metric traits. Additionally, no comparative specimen from any taxa was found to lack a hypoconulid, but express an MTC, demonstrating LYC1's uniqueness.

Compared to other Late Pleistocene East Asian fossil H. sapiens, the Laoya Cave $\mathrm{M}_{3}$ is distinctive. The talonids of the fossil H. sapiens from Daoxian Fuyan Cave, Tianyuan Cave, Huanglong Cave, and Maludong are enlarged, and in some cases the talonid is even larger than the trigonid, whereas the LYC1 has a narrowed talonid. $\mathrm{M}_{3}$, with a buccolingually narrowed talonid, and a resultant triangle crown outline shape, could have been a typical feature in East Asian Early and Middle Pleistocene and other earlier hominins. $\mathrm{M}_{3} \mathrm{~s}$ of some recent Homo groups (Neanderthals, fossil $H$. sapiens, and recent $H$. sapiens) tend to have an enlarged talonid relative to the trigonid, though $\mathrm{M}_{3}$ crown outlines are quite variable. The $\mathrm{M}_{3} \mathrm{~s}$ of other East Asian fossil H. sapiens are characterized by multiple cusps, and all include a hypoconulid, unlike LYC1 for which the hypoconulid is absent. 
Mtg 1 and Mtg C of Minatogawa hominins also develop a hypoconulid in their $\mathrm{M}_{3} \mathrm{~s}$ (see Figure 2 and Figure 4 in Kaifu et al. (2011)). Additionally, extra cusps like C6 and/or C7 are present in the $\mathrm{M}_{3} \mathrm{~s}$ of the Daoxian Fuyan and Huanglong caves (Liu et al., 2010b, 2015). The MTC, which is highly rare in East Asian Middle Pleistocene fossil hominins (see Xing et al., 2014; Liu et al., 2017) and absent from all the specimens of East Asian fossil H. sapiens, appears in LYC1. A high and continuous MTC of the lower molar is frequently found in specimens of Neanderthal lineage (Bailey et al., 2011; Martínez de Pinillos et al., 2014). However, a continuous MTC also exists in Australopithecus and Sangiran Early Pleistocene hominins (Kaifu et al., 2005; MoggiCecchi et al., 2006). Finally, the linear type of extreme enamel extension detected in East Asian fossil $H$. sapiens from Daoxian Fuyan Cave and Huanglong Cave (Liu et al., 2010b, 2015), is not present in the LYC1 M

The AMS dating of mammalian bones extracted from consecutive layers of the Laoya Cave deposits have provided a very continuous dispositional sequence and reliable chronology. The reliability of the dating at this site is especially important compared to the absence of stratigraphic backgrounds and/or reliable dating results for the majority of East Asian fossil H. sapiens (Wu and Poirier, 1995). The LYC1 permanent $\mathrm{M}_{3}$ includes morphological characteristics that are common in other East Asian Late Pleistocene hominins, but its distinctive suite of traits expands the known morphological diversity among the East Asian Late Pleistocene hominins (Liu et al., 2010a, 2010b, 2015; Curnoe et al., 2012; Wu et al., 2012, 2014; Wu and Trinkaus, 2014; Xing et al., 2015). However, we should be cautious not to overstate LYC1's exceptionality because it is not unusual for a particular combination of traits to only appear in one individual (SI Table 4). Although rare, the dental morphology of LYC1, combined with other findings from the Zhiren, Huanglong, and Fuyan caves, suggests a more expanded morphological diversity in East Asia, including some archaic characteristics, than previously recognized (Liu et al., 2010a; present study). Similarly, recent DNA studies of southeastern Islanders have revealed a more archaic signature unknown previously and have expanded further the genetic diversity of recent H. sapiens (Skoglund et al., 2015; Pagani et al., 2016; Vernot et al., 2016). New findings of fossil hominins with secure dates and stratigraphic contexts such as the Laoya Cave site, and molecular studies of more specimens of modern humans, either fossilized or extant, may reveal more unique or surprising phenotypes. All these will certainly contribute to a better understanding of modern human evolution in East or Southeast Asian.

\section{Acknowledgments}

The authors would like to thank all their colleagues who have helped us to accomplish this study. Dr. María Martinón-Torres shared some of the photos of Neanderthals and European fossil $H$. sapiens, and kindly gave us valuable suggestions to improve the quality of this manuscript. We also express our gratitude to several people for providing access to the study materials and their helpful assistance during observations: Dr Ron Clarke (University of the Wit- watersrand, South Africa), Dr Xueping Ji (Yunnan Institute of Cultural Relics and Archeology, Kunming), Dr Wei Wang (Guangxi Museum of Nationalities, Nanning), Dr Yousuke Kaifu (National Museum of Nature and Science, Tokyo), Dr Mi Zhou (Institute of Archeology and Cultural Relics of Hubei Province, Wuhan). Dr Milford Wolpoff provided dental metric data. We also want to thank Dr Debbie GuatelliSteinberg and Dr Lei Pan for their continued support during this study. This work has been supported by the National Basic Research Program ofChina(Grant No. 2015CB953803). This work is also supported by NSF Foundation Graduate Research Fellowship Program Grant No. DGE-1343012 to Mackie O'Hara. Any opinions, findings, and conclusions or recommendations expressed in this material are those of the author and do not necessarily reflect the views of the National Science Foundation.

\section{References}

Bae C.J., Wang W., Zhao J., Huang S., Tian F., and Shen G. (2014) Modern human teeth from Late Pleistocene Luna Cave (Guangxi, China). Quaternary International, 354: 169-183.

Bailey S.E., Skinner M.M., and Hublin J.-J. (2011) What lies beneath? An evaluation of lower molar trigonid crest patterns based on both dentine and enamel expression. American Journal of Physical Anthropology, 145: 505-518.

Bookstein F.L. (1991) Morphometric Tools for Landmark Data: Geometry and Biology. Cambridge University Press, Cambridge.

Curnoe D., Xueping J., Herries A.I., Kanning B., Taçon P.S., Zhende B., Fink D., Yunsheng Z., Hellstrom J., Yun L., Cassis G., Bing S., Wroe S., Shi H., Parr W.C., Shengmin H., and Rodgers N. (2012) Human remains from the PleistoceneHolocene transition of southwest China suggest a complex evolutionary history for East Asians. PLoS One, 7: e31918.

Gómez-Robles A., Bermúdez de Castro J.M., Martinón-Torres M., Prado-Simón L., and Arsuaga J.L. (2015) A geometric morphometric analysis of hominin lower molars: evolutionary implications and overview of postcanine dental variation. Journal of Human Evolution, 82: 34-50.

Grine F.E. and Franzen J.L. (1994) Fossil hominid teeth from the Sangiran Dome (Java, Indonesia). Courier Forsch Senckenberg, 171: 75-103.

Guan Y., Cai H., Wang X., Xu C., Zheng Y., Zhang Z., Xing S., and Gao X. (2015) A preliminary report of the Laoya Cave Late Paleolithic site in Bijie, Guizhou Province. Acta Anthropologica Sinica, 34: 461-478.

Huang X. (1989) A skull of fossil H. sapiens from Chuandong Cave, Puding County, Guizhou Province. Acta Anthropologica Sinica, 8: 379-381.

Kaifu Y., Aziz F., and Baba H. (2005) Hominid mandibular remains from Sangiran: 1952-1986 collections. American Journal of Physical Anthropology, 128: 497-519.

Kaifu Y., Fujita M., Kono R.T., and Baba H. (2011) Late Pleistocene modern human mandibles from the Minatogawa Fissure site, Okinawa, Japan: morphological affinities and implications for modern human dispersals in East Asia. Anthropological Science, 119: 137-157.

Kaifu Y., Kono R.T., Sutikna T., Saptomo E.W., Jatmiko, and Awe A.R. (2015) Unique dental morphology of Homo floresiensis and its evolutionary implications. PLoS One, 10: e0141614.

Kono R.T. (2004) Molar enamel thickness and distribution patterns in extant great apes and humans: new insights based on a 3dimensional whole crown perspective. Anthropological Science, $112,121-146$.

Korenhof C.A.W. (1982) Evolutionary trends of the inner enamel anatomyof deciduous molars from Sangiran (Java, Indonesia). In: Kurten B. (ed.), Teeth: Form, Function and Evolution. 
Columbia University Press, New York, pp. 350-365.

Li Z.Y., Wu X.J., Zhou L.P., Liu W., Gao X., Nian X.M., and Trinkaus E. (2017) Late Pleistocene archaic human crania from Xuchang, China. Science, 355: 969-972.

Liu W., Jin C.-Z., Zhang Y.-Q., Cai Y.-J., Xing S., Wu X.-J., Cheng H., Edwards R.L., Pan W.-S., Qin D.-G., An Z.-S., Trinkaus E., and $\mathrm{Wu} \mathrm{X.} \mathrm{(2010a)} \mathrm{Human} \mathrm{remains} \mathrm{from} \mathrm{Zhirendong,}$ South China, and modern human emergence in East Asia. Proceedings of the National Academy of Sciences of the United States of America, 107: 19201-19206.

Liu W., Wu X.Z., Pei S.W., Wu X.J., and Norton C.J. (2010b) Huanglong Cave: a Late Pleistocene human fossil site in $\mathrm{Hu}-$ bei Province, China. Quaternary International, 211: 29-41.

Liu W., Martinón-Torres M., Cai Y.J., Xing S., Tong H.W., Pei S.W., Sier M.J., Wu X.H., Edwards R.L., Cheng H., and Li Y.Y. (2015) The earliest unequivocally modern humans in southern China. Nature, 526: 696-699.

Liu W., Martinón-Torres M., Kaifu Y., Wu X., Kono R.T., Chang, C.H., Wei P., Xing S., Huang W., and Bermúdez de Castro J.M. (2017) A mandible from the Middle Pleistocene Hexian site and its significance in relation to the variability of Asian Homo erectus. American Journal of Physical Anthropology, 162: 715-731.

Martínez de Pinillos M., Martinón-Torres M., Skinner M.M., Arsuaga J.L., Gracia-Téllez A., Martínez I., Martín-Francés L., and Bermúdez de Castro J.M. (2014) Trigonid crests expression in Atapuerca-Sima de los Huesos lower molars: Internal and external morphological expression and evolutionary inferences. Comptes Rendus Palevol, 13: 205-221.

Martinón-Torres M., Bermúdez de Castro J.M., Gómez-Robles A., Prado-Simón L., and Arsuaga J.L. (2012) Morphological description and comparison of the dental remains from Atapuerca-Sima de los Huesos site (Spain). Journal of Human Evolution, 62: 7-58.

Matsumura H. and Oxenham M.F. (2014) Demographic transitions and migration in prehistoric East/Southeast Asia through the lens of nonmetric dental traits. American Journal of Physical Anthropology, 155: 45-65.

Moggi-Cecchi J., Grine F.E., and Tobias P.V. (2006) Early hominid dental remains from Members 4 and 5 of the Sterkfontein Formation (1966-1996 excavations): Catalogue, individual associations, morphological descriptions and initial metrical analysis. Journal of Human Evolution, 50: 239-328.

Molnar S. (1971) Human tooth wear, tooth function and cultural variability. American Journal of Physical Anthropology, 34: $175-189$.

Olejniczak A.J. (2006) Micro-computed tomography of primate molars. Ph.D. thesis, State University of New York at Stony Brook.

Olejniczak A.J., Smith T.M., Feeney R.N.M., Macchiarelli R., Mazurier A., Bondioli L., Rosas A., Fortea J., de la Rasilla M., Garcia-Tabernero A., Radovčić J., Skinner M.M., Toussaint M., and Hublin J.-J. (2008) Dental tissue proportions and enamel thickness in Neandertal and modern human molars. Journal of Human Evolution, 55: 12-23.

Pagani L., Lawson D.J., Jagoda E., et al. (2016) Genomic analyses inform on migration events during the peopling of Eurasia. Nature, 538: 238-242.

Pan L., Dumoncel J., Beer F.D., Hoffman J., Thackeray J.F., Duployer B., Tenailleau C., and Braga J. (2016) Further morphological evidence on South African earliest Homo, lower postcanine dentition: enamel thickness and enamel dentine junction. Journal of Human Evolution, 96: 82-96.

Rightmire G.P. and Deacon H.J. (1991) Comparative studies of Late Pleistocene human remains from Klasies River Mouth, South Africa. Journal of Human Evolution, 20: 131-156.

Rohlf F.J. (1998a) TpsDig2. Ecology and Evolution, State University of New York at Stony Brook. http://life.bio.sunysb.edu/morph/

Rohlf F.J. (1998b) TpsRelw. Ecology and Evolution, State University of New York at Stony Brook. http://life.bio.sunysb.edu/ morph/

Skoglund P., Mallick S., Bortolini M.C., Chennagiri N., Hunemeier
T., Petzl-Erler M.L., Salzano F.M., Patterson N., and Reich D. (2015) Genetic evidence for two founding populations of the Americas. Nature, 525: 104-108.

Smith T.M., Olejniczak A.J., Zermeno J.P., Tafforeau P., Skinner M.M., Hoffmann A., Radovčić J., Toussaint M., Kruszynski R., Menter C., Moggi-Cecchi J., Glasmacher U.A., Kullmer O., Schrenk F., Stringer C., and Hublin J.-J. (2012) Variation in enamel thickness within the genus Homo. Journal of Human Evolution, 62: 395-411.

Tobias P.V. and Koenigswald G.H.R.V. (1964) A comparison between the Olduvai hominines and those of Java and some implications for hominid phylogeny. Current Anthropology, 6: 427-431.

Turner C.G., II (1987) Late Pleistocene and Holocene population history of East Asia based on dental variation. American Journal of Physical Anthropology, 73: 305-321.

Turner C.G., II, Nichol C.R., and Scott G.R. (1991) Scoring procedures for key morphological traits of the permanent dentition: the Arizona State University dental anthropology system. In: Kelley M. and Larsen C.S. (eds.). Advances in Dental Anthropology. Wiley-Liss, New York, pp. 13-31.

Vernot B., Tucci S., Kelso J., Schraiber J.G., Wolf A.B., Gittelman R.M., Dannemann M., Grote S., McCoy R.C., Norton H., Scheinfeldt L.B., Merriwether D.A., Koki G., Friedlaender J.S., Wakefield J., Pääbo S., and Akey J.M. (2016) Excavating Neandertal and Denisovan DNA from the genomes of Melanesian individuals. Science, 352: 235-239.

Wang L., Peng S., and Chen Y. (1982) On the human fossils and stone artifacts from Baojiyan, Guilin. Acta Anthropologica Sinica, 1: 30-35.

Wang W. and Mo J. (2004) Human fossil teeth newly discovered in Nanshan Cave of Fusui, Guangxi. Acta Anthropologica Sinica, 23: 130-137.

Wang W., Huang C., Xie S., and Yan C. (2011) Late Pleistocene hominin teeth from the Jimuyan Cave, Pingle County, Guangxi, southern China. Quaternary Science, 31: 699-704.

Wang X., Guan Y., Cai H., Costamagno S., Zhang L., Xu C., and Gao X. (2016) Diet breadth and mortality patterns from Laoya Cave: a primary profile of MIS 3/2 hunting strategies in the Yunnan-Guizhou Plateau, southwest China. Science China Earth Sciences, 59: 1642-1651.

Wolpoff M. (1971) Metric Trends in Hominid Dental Evolution. Case Western Reserve University Press, Cleveland, $\mathrm{OH}$.

Wu X. and Poirier F. (1995) Human Evolution in China: A Metric Descrition of Fossils and a Review of the Sites. Oxford University Press, Oxford.

Wu X. and Trinkaus E. (2014) The Xujiayao 14 mandibular ramus and Pleistocene Homo mandibular variation. Comptes Rendus Palevol, 13: 333-341.

Wu X.-J., Maddux S.D., Pan L., and Trinkaus E. (2012) Nasal floor variation among eastern Eurasian Pleistocene Homo. Anthropological Science, 120: 217-226.

Wu X.-J., Crevecoeur I., Liu W., Xing S., and Trinkaus E. (2014) Temporal labyrinths of eastern Eurasian Pleistocene humans. Proceedings of the National Academy of Sciences of the United States of America, 111: 10509-10513.

Xing S., Martinón-Torres M., Bermúdez de Castro J.M., Zhang Y., Fan X., Zheng L., Huang W., and Liu W. (2014) Middle Pleistocene hominin teeth from Longtan Cave, Hexian, China. PLoS One, 9: e114265.

Xing S., Martinón-Torres M., Bermúdez de Castro J.M., Wu X., and Liu W. (2015) Hominin teeth from the early Late Pleistocene site of Xujiayao, Northern China. American Journal of Physical Anthropology, 156: 224-240.

Zanolli C. (2013) Additional evidence for morpho-dimensional tooth crown variation in a new Indonesian $H$. erectus sample from the Sangiran Dome (Central Java). PLoS One, 8: e67233.

Zanolli C. (2015) Molar crown inner structural organization in Javanese Homo erectus. American Journal of Physical Anthropology, 156: 148-157. 